\title{
It's 2 x 2 Designs All The Way Down: \\ Social Psychology's Over-Reliance on Experiments Needlessly Restricts Diversity in the Field
}

\author{
Moin Syed \\ University of Minnesota \\ moin@umn.edu
}

This is an elaborated version of a talk presented as part of the invited symposium:

Time for change, Part II: Creating a more diverse, rigorous, and responsive discipline

Chaired by Neil Lewis, Jr.

Society for Personality and Social Psychology 2021 Annual Conference

Version Date: February 5, 2021

Slides, video, and this essay available at: https://osf.io/gc3mu/

Thanks to Maimoua Hoang for help with gathering the data included in this paper. This is essay No. 6 in the series, "I Got A Lot of Problems with Psychology."

It should be clear from the title that this talk will not be particularly positive towards social psychology. I myself am not a social psychologist. I was trained as a cultural developmental psychologist, and these days I also identify as a personality psychologist and as a generalist. But I am definitely an outsider to social psychology and SPSP. That gives me some license to be a bit incendiary, which I think you all need. At the same time, it makes it easy to dismiss my criticisms. I hope you will not do that, pointing to the few exceptions to what I claim, but rather see the spirit of this talk for what it is: a call to make things better. It is also worth noting that nearly everything I say today has in fact been said previously by social psychologists. I am mostly just aggregating. I also want to assure you that my criticisms are not because of any special vendetta I have against social psychology. Indeed, I have similarly criticized developmental (Syed et al., 2018), personality (Syed, 2021), and the psychology field as a whole (Syed 2017). We all have problems.

The problem that I am focusing on today is the problem of diversity, and specifically the problem of diversity in social psychology. The framing that I use here is U.S.-focused, and whereas the specific examples are rooted in the U.S., the general points are widely applicable. The charts and graphs all bear out the problem of diversity (Hartmann, et al., 2013; Roberts, et al., 2020; Figure 1), that a field that is heavily concerned with diversity-related topics is not doing particularly well on the diversity front. On its face, social psychology should really be one 
of the biggest attractors of students of color and a leader throughout psychology, providing lessons to other areas about how to improve. But it's not.

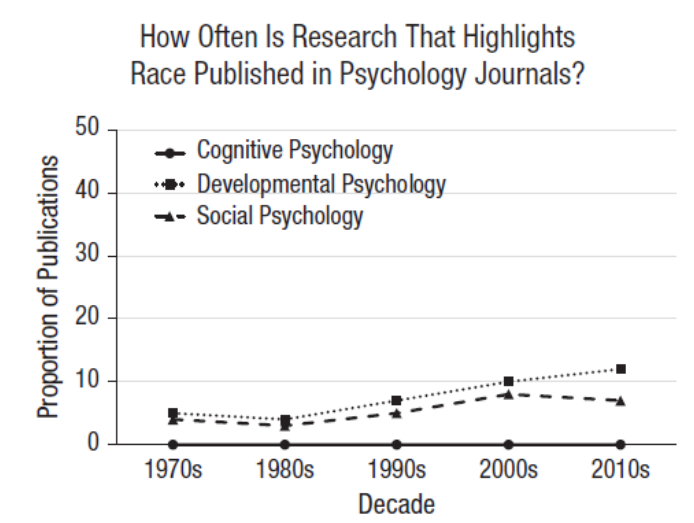

Fig. 1. Proportion of publications that highlighted race across five decades of publications in cognitive, developmental, and social psychology.

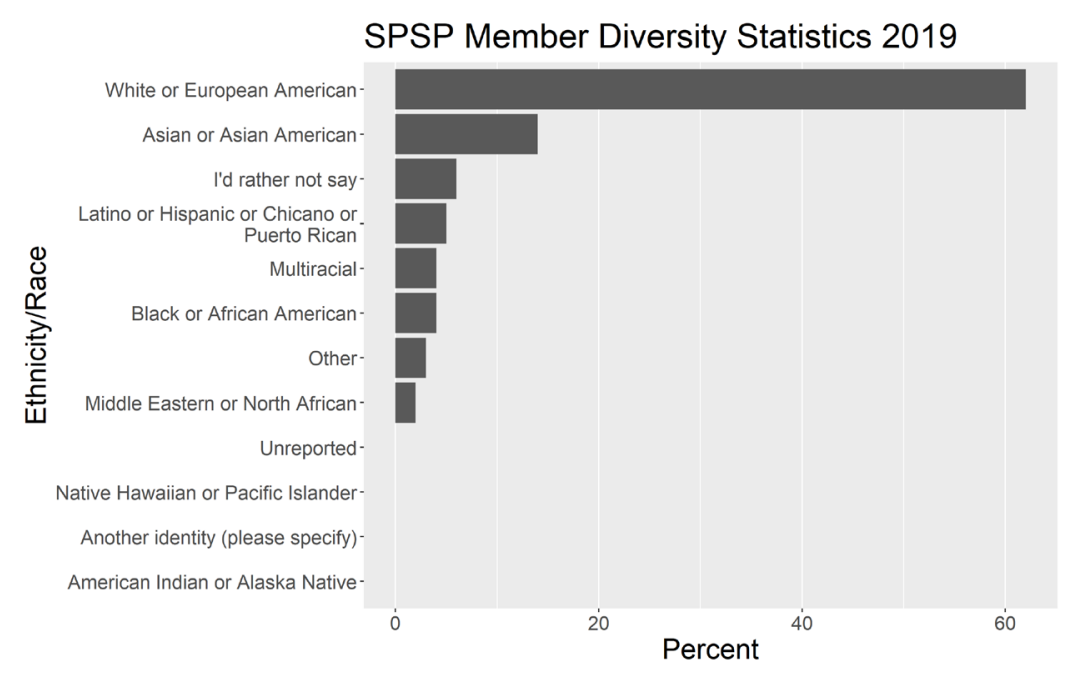

Figure 1. Left panel from Roberts et al. (2020). Right panel based on data from https://spsp.org/sites/default/files/Member-Diversity-Statistics-December-2019.pdf

Why? Certainly, there is no singular reason, but because this is a very brief essay, I will pretend like there is: the overreliance on experiments in the field. I am not claiming that this explains everything, but it can surprisingly explain a lot. Moreover, plenty of social psychologists have criticized the heavy emphasis on lab experiments, but these criticisms have been mostly in terms of external validity (Baumeister et al., 2006; Cialdini, 2009; Dasgupta \& Stout, 2012; Mortensen \& Cialdini, 2010). My points are somewhat different:

1. The emphasis on experiments restricts diversity in the field

2. The emphasis on experiments is scientifically unjustifiable

No one would seriously dispute the fact of the dominance of experiments in social psychology (see Rozin, 2001, for some data). This is especially true in U.S.-based social psychology; the discipline in other parts of the world tends to be more methodologically diverse, although experiments are still highly valued.

But how did we get here? There are several sources that outline the slow march to experimental dominance, but I like House (1977) and Oishi et al. (2009), both of which pertain to the relation between social psychology and sociology. Oishi et al., claimed that "social psychologists don't like history," so if true many might not know much about this divergence of disciplines over time. That is really a separate issue, so for now I will just say that the consolidation of experiments as the core method in the field played a central role. Now, one might reasonably argue that the divergence was motivated by social psychologists' interest in 
more immediate situational contexts, which leant themselves well to conducting experiments. But the evidence favors the opposite causal direction, that the desire to conduct experiments required that studies focus on micro contexts in the lab (or the field, but even that got pushed out, see Cialdini, 2009).

Why did social psychologists desire to conduct experiments? I obviously don't have access to their mental states, and even if I did, I have learned from social psychologists not to trust them. However, the historical evidence suggests that a primary driver for this move was our old friend physics envy. Yes friends, as psychology was coming into its own as a discipline, searching for a coherent identity, it turned to the natural sciences for guidance, and found its answer: emphasizing causal mechanisms via experimentation would allow psychology to join the ranks of real science, to shore up its position in the hierarchy (House, 1977; Rozin, 2001).

Ok but what does this have to do with diversity?

The over-reliance on experiments necessarily constrains the type of questions one is willing to ask. That is just a fact. If the primary way in which you approach your understanding of psychological phenomena is to determine how you can fit it into a $2 \times 2$ experiment, then you are cutting your science off from a wide variety of interesting questions. Many of these unthinkable questions will be just the kind that many minority students will be interested in, those that were informed by their personal experiences or observations (Syed, 2017). As an example, one of my mentors Dr. Linda Juang got into the field because she wanted to better understand the psychological reasons for why she had experienced conflict with her immigrant parents when she was an adolescent. This is not the kind of question that can be answered with an experiment. She, and many others with similar motivations, got into developmental psychology, where there is now a thriving science of diversity focusing on topics of identity, acculturation, schooling, discrimination, socialization, and so on.

But surely, you are saying to yourself, social psychology studies discrimination, prejudice, stereotyping--all topics that minority students are likely to be interested in. And yes, you are correct. However, such work in social psychology far and away focuses on the perpetrators, not the targets, with more than half of studies pertaining to race relying on White participants (Germano \& Cheryan, 2021; Roberts et al., 2020). Moreover, this rate is similar across White and minority authors. In contrast, in developmental research the majority of work on race includes minority samples, and this is especially the case for minority authors (Roberts et al., 2020). Thus, even when studying topics of core interest and relevance to minority populations, social psychology still does so with White participants!

This seems like a strange thing to do. Of course we should study perpetrators, and majority groups in general, when trying to understand experiences that are highly relevant to minorities. But such a disproportionate focus? Why? 
You guessed it, experiments! Conducting lab-based experiments results in a heavy reliance on who is nearby and available for participation ${ }^{1}$. By this of course I mean college students. There is a reason that Arnett (2008) suggested that JPSP should be renamed the Journal of the Personality and Social Psychology of American Undergraduate Introductory Psychology Students. We pulled some data on the top 30 psychology programs in the U.S. based on the U.S. News and World Report Rankings. First thing to note is that the publicly-reported data by universities is extremely unclear and inconsistent, turning a rather simple task into a more complex one. For this reason, here I only highlight the top 5 programs. The left panel of Figure 2 shows the distribution for White, Asian American, and non-Asian Students of Color (these data do not include international students) ${ }^{2}$. The data suggest reasonable diversity at some of the schools, but also clearly a restricted participant pool at some of them (especially given the size of Stanford and Harvard).
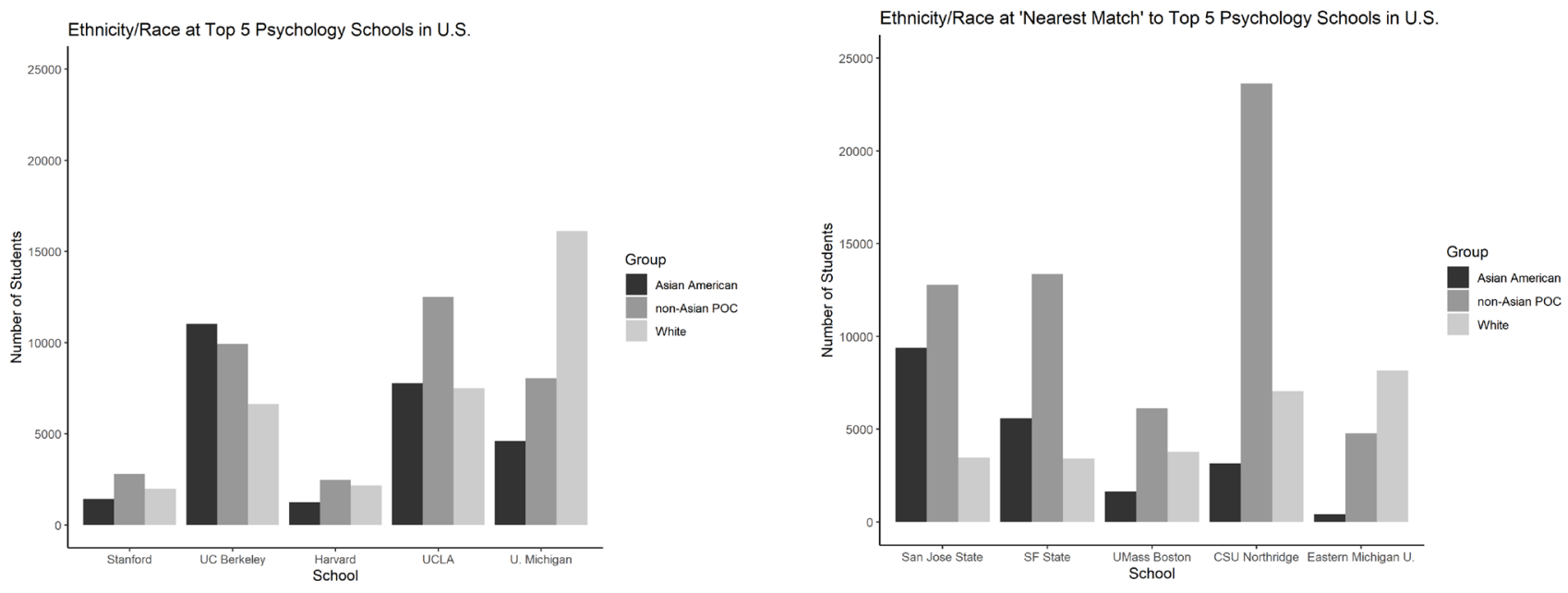

Figure 2. Ethnicity/Race for a set of universities in the U.S.

However, it may come as a shock to many of you that other institutions exist, and sometimes they are quite close by. We located a "nearest-neighbor" 4-year institution to the top 30 list, most of which were within 5 miles of each other (except Illinois, nothing is near that). Comparing the top 5 nearest neighbors, we see quite a different picture. Not only do these schools have higher proportions of non-Asian Students of Color, but they are generally much larger, so the raw pool is bigger. Many of these institutions would likely be happy to partner up, as long as it was part of a broader mutually beneficial arrangement and not just a route for the elite institutions to get what they need. Of course, there are many other nearby institutions other than these, and there are community colleges all over the place (and of course, people not in college). Thus, there is no lack of opportunity to diversify even within the experimental context, but it does require a little bit of extra effort.

\footnotetext{
${ }^{1}$ Worth noting that developmental psychology also has this problem, relying on university-based laboratory preschools and other approaches that all but ensure lack of diversity. Thus, this particular problem is one of experiments more broadly.

${ }^{2}$ Here goes the standard disclaimer that the way we categorize groups is arbitrary and obscures within-group heterogeneity. Go ahead and categorize them however you want, the same general picture will emerge.
} 
All of the preceding is precisely why social psychology went all in on implicit bias, despite the fact that its validity and utility was shaky from the beginning (Schimmack, 2019), and it is clearly less effective as a point of intervention vs. targeting the kind of structural factors that social psychologists generally don't study (Onyeador et al., 2021). The subject was interesting, to be sure, but the studies were doable within the current framework of the field. We are now collectively undoing the damage of that choice. All in all, it seems clear that methods are driving the substantive focus of the field.

Ok you say, but experiments! Experiments are the currency of science, causation and all of that. What is more scientific than experiments? I'll tell you: asking good questions, and using methods that are well-suited to addressing them. There is no singular definition of social psychology, but something like this is likely not objectionable:

Social psychology is the scientific study of how we feel about, think about, and behave toward the people around us and how our feelings, thoughts, and behaviors are influenced by those people. (Stangor, 2014)

What about that definition suggests the need for experiments? Of course they play a role, even a big role, but not the outsize role that they play today. This is especially the case in the context of current knowledge in the field. We can generally think of a scientific field as consisting of five sequential steps: observation, description, explanation, prediction, and control. Some people argue about the order of explanation and prediction, that observations cannot be made outside of theories, that the steps are not particularly linear, and so on. Those issues are not central to the main point, which is that social psychology spends almost all of its time at the explanation step-conducting experiments, seeking causal mechanisms-and almost no time at all on the observation and description steps. This is of course a more general problem in the field-many of us have received negative editorial decisions or reviewer comments because a project was "just descriptive." The problem, then, is that we are seeking to understand causal relations among constructs that we do not sufficiently understand (Mortensen \& Cialdini, 2010; Rozin, 2001; Scheel et al., 2021). That is not good science.

Indeed, the experimental focus has served as a cover for other problematic practices. Researchers conduct experiments because they are rigorous and to establish causation, but then do a $2 \times 2$ with 10 White undergraduates per cell. This all looks a lot like playing science rather than doing science, driven by our ever-present companion physics envy. In 2009, Oishi et al. wrote:

Zimbardo (1999) noted, "Sociologists asked the big questions but never quite had good enough answers, whereas it became evident that psychologists were asking low-level questions but were good at methodology and analysis" (p. 143). Imaginative experimental designs combined with analytical sophistication allowed the accumulation of an impressive body of knowledge and led to a strong field of social psychology with increasing impact and interdisciplinary activity. 
This statement was made on the precipice of the replication crisis, and I think that there is plenty of accumulated evidence to indicate social psychologists were/are not as good at methodology and analysis as they proclaimed, and they have not provided a particularly impressive body of knowledge. So where has the misplaced over-emphasis on experiments got the field? Not as far as anyone would like. So why not try something different? Even papers that have been highly critical of the experimental emphasis in the field argue for better experiments, not different methods (Baumeister et al., 2006). Why not better integrate other methodological approaches into the field-including qualitative and mixed methods? What is the real risk? Other than perceptions of status, there is no risk, yet there are numerous benefits to expanding the methodological repertoire.

\section{Coda}

My first memory of SPSP is being told that the first "P" (for personality) is silent. I find the dynamic between social and personality to be odd and troubling. Within the society and the field there is an explicit hierarchy that few are ashamed to voice and reinforce. And indeed, social psychology has a hierarchy problem: emphasis on super stars and rising stars, academic celebrity encounters, treating some folks and some ideas as infallible, treating one (overrated) journal as a critical marker of success, compromising scientific rigour for media attention. None of these are healthy. Not for science, and certainly not for diversity. This is not to say that social psychology is the only field with a hierarchy problem, but it is certainly more stark than other areas. SPSP and other social psychology organizations are launching a number of initiatives to improve diversity, but none of them will enact real change. You need structural change, to bring down these hierarchies, and ceasing to act as though experiments are a sign of rigour is a good place to start. 


\section{References}

Arnett, J. J. (2008). The neglected 95\%: Why American psychology needs to become less American. American Psychologist, 63(7), 602-614. https://doi.org/10.1037/0003066X.63.7.602

Baumeister, R. F., Vohs, K. D., \& Funder, D. C. (2007). Psychology as the Science of Self-Reports and Finger Movements: Whatever Happened to Actual Behavior? Perspectives on Psychological Science, 2(4), 396-403. https://doi.org/10.1111/j.1745-6916.2007.00051.x

Cialdini, R. B. (2009). We Have to Break Up. Perspectives on Psychological Science, 4(1), 5-6. https://doi.org/10.1111/j.1745-6924.2009.01091.x

Dasgupta, N., \& Stout, J. G. (2012). Contemporary Discrimination in the Lab and Field: Benefits and Obstacles of Full-Cycle Social Psychology. Journal of Social Issues, 68(2), 399-412. https://doi.org/10.1111/j.1540-4560.2012.01754.x

Hartmann, W. E., Kim, E. S., Kim, J. H. J., Nguyen, T. U., Wendt, D. C., Nagata, D. K., \& Gone, J. P. (2013). In Search of Cultural Diversity, Revisited: Recent Publication Trends in CrossCultural and Ethnic Minority Psychology. Review of General Psychology, 17(3), 243-254. https://doi.org/10.1037/a0032260

House, J. S. (1977). The Three Faces of Social Psychology. Sociometry, 40(2), 161-177. https://doi.org/10.2307/3033519

Mortensen, C. R., \& Cialdini, R. B. (2010). Full-Cycle Social Psychology for Theory and Application. Social and Personality Psychology Compass, 4(1), 53-63. https://doi.org/10.1111/j.1751-9004.2009.00239.x

Oishi, S., Kesebir, S., \& Snyder, B. H. (2009). Sociology: A Lost Connection in Social Psychology. Personality and Social Psychology Review, 13(4), 334-353. https://doi.org/10.1177/1088868309347835

Onyeador, I. N., Hudson, S. T. J., \& Lewis, Jr., N. A. (2021). Moving beyond implicit bias training: Policy insights for increasing organizational diversity. Policy Insights for the Brain and Behavioral Sciences.

Roberts, S. O., Bareket-Shavit, C., Dollins, F. A., Goldie, P. D., \& Mortenson, E. (2020). Racial Inequality in Psychological Research: Trends of the Past and Recommendations for the Future. Perspectives on Psychological Science, 15(6), 1295-1309. https://doi.org/10.1177/1745691620927709 
Rozin, P. (2001). Social Psychology and Science: Some Lessons From Solomon Asch. Personality and Social Psychology Review, 5(1), 2-14.

https://doi.org/10.1207/S15327957PSPR0501_1

Scheel, A. M., Tiokhin, L., Isager, P. M., \& Lakens, D. (2020). Why Hypothesis Testers Should Spend Less Time Testing Hypotheses. Perspectives on Psychological Science. https://doi.org/10.1177/1745691620966795

Schimmack, U. (2019). The Implicit Association Test: A Method in Search of a Construct. Perspectives on Psychological Science. https://doi.org/10.1177/1745691619863798

Stangor, C. (2014). Principles of Social Psychology-1st International Edition. BCcampus. https://opentextbc.ca/socialpsychology/

Syed, M. (2017). Why Traditional Metrics May Not Adequately Represent Ethnic Minority Psychology. Perspectives on Psychological Science, 12(6), 1162-1165. https://doi.org/10.1177/1745691617709590

Syed, M. (2021). Where are Race, Ethnicity, and Culture in Personality Research? PsyArXiv. https://doi.org/10.31234/osf.io/m57ph

Syed, M., Santos, C., Yoo, H. C., \& Juang, L. P. (2018). Invisibility of racial/ethnic minorities in developmental science: Implications for research and institutional practices. American Psychologist, 73(6), 812-826. https://doi.org/10.1037/amp0000294 